\title{
RELEITURAS DE OBRAS LITERÁRIAS NACIONAIS NA PRODUÇÃO DE JOGOS DIGITAIS
} Andrẽ Luiz França Batista*

(iD http://orcid.org/0000-0003-3225-8359

Rodrigo Grassi Martins**

(iD) http://orcid.org/0000-0002-9975-1044

Como citar este artigo: BATISTA, A. L. F.; MARTINS, R. G. Releituras de obras literárias nacionais na produção de jogos digitais. Todas as Letras - Revista de Lingua e Literatura, São Paulo, v. 23, n. 2, p. 1-13, maio/ago. 2021. DOI 10.5935/1980-6914/ eLETOL2 113327

Submissão: abril de 2020. Aceite: março de 2021.

Resumo: Neste artigo descrevemos uma possibilidade de estabelecer uma conexão sólida entre literatura e algoritmos. Relatamos aqui uma experiência acadêmica interdisciplinar envolvendo discentes do curso de nivel técnico em Informática, na qual eles realizaram a adaptação transmídia de obras literárias de autores nacionais para jogos digitais produzidos pelos próprios alunos. As análises mostram que essa ação didático-pedagógica melhorou o engajamento estudantil em relação ao conteúdo das unidades curriculares, e estabelece uma conexão eficaz entre literatura e algoritmos.

Palavras-chave: Literatura nacional. Algoritmos. Jogos digitais. Práticas pedagógicas. Interdisciplinaridade. 


\section{INTRODUÇÃo}

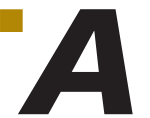

tualmente, o desenvolvimento e a contínua utilização das tecnologias da informação e comunicação (TICs) transformaram muitos comportamentos em nossa vida e fomentaram abordagens de ensino e aprendizagem cada vez mais interativas, dinâmicas e diversificadas, atreladas ao cenário de uso da linguagem pelos sujeitos participantes. As tecnologias digitais estão cada vez mais presentes no ambiente escolar, e mesmo quando o docente não se apodera das tecnologias digitais dentro do contexto educacional, o aluno se encarrega de fazê-lo (MARTINS, 2015).

O cenário social e tecnológico em que vivemos atualmente é determinado, em sua essência, pelo surgimento do ciberespaço, meio de comunicação que surge a partir da rede mundial dos computadores (LÉVY, 2005), e é compreendido como uma concepção da sociedade em rede, na qual fluxos de informações (CASTELLS, 2010) arquitetam novos meios de relações sociais, econômicas, políticas, profissionais, acadêmicas, moldando novos atributos à sociedade. Podemos experimentar um novo relacionamento entre as tecnologias digitais em rede e os meios de comunicação, fomentados pela utilização dos dispositivos móveis, transformando os espaços urbanos.

É significativa a relevância que os meios digitais têm atualmente em nossa sociedade. Cada vez mais, os artefatos digitais e seus algoritmos estão à nossa volta, permeando nosso cotidiano - às vezes, até mesmo sem o nosso conhecimento (BATISTA; BAZZO, 2015). As diversas telas, computadores e dispositivos móveis têm, como parte essencial para seu funcionamento e performance, os seus algoritmos. Os algoritmos são, em uma definição informal, "um conjunto de regras que define com precisão uma sequência de operações" (CORMEN et al., 2002), incluindo todos os programas de computador, mesmo aqueles programas que não realizam cálculos numéricos, e quaisquer processamentos de dados.

A leitura, segundo Souza (2020), era percebida pelas gerações anteriores como manifestação da expressão identitária, ou como forma de resistência contra repressão familiar e social. Porém, recentemente, a arte literária tem se apropriado de novos meios para produção e leitura e, por isso, o docente pode propor atividades que envolvam os sujeitos em práticas interativas, com o intuito de promover o desenvolvimento sociocultural dos indivíduos por meio de circunstâncias reais de uso da língua (DOS SANTOS, 2018). Sendo assim, é importante discutir como as interfaces digitais podem enriquecer as iniciativas de leituras de obras literárias no ambiente escolar, colaborando com o processo de ensino e aprendizagem, inclusive nos cursos de nivel técnico. Acredita-se, sobretudo, que o uso dos recursos digitais, entre outros elementos, favorece o processo de letramento, uma vez que também possibilita o uso social da linguagem escrita, em situação concreta, incorporada a uma necessidade discursiva.

Hoje, há leitores digitais, livros e outras obras literárias em formatos digitais diversos (SERRA; SANTARÉM, 2017). Entretanto, na atualidade, a leitura corre o risco de ser considerada como um ato de submissão, prática obrigatória atrelada a fins educacionais ou profissionais, dissociando-se a leitura do entretenimento. No ato obrigatório de leitura de certos gêneros literários e determinados autores, falha-se o encontro oportunizado pelos livros. Para alcançar os jovens, que estão conectados à rede praticamente o tempo todo e demandam acesso à 
informação em tempo real e imediato, muitos esforços têm sido feitos para desenvolver livros e obras literárias e atender esse grupo (SOUZA, 2020; DOS SANTOS, 2018; SERRA; SANTARÉM, 2017).

Baseando-se na premissa de que a prática pedagógica pode possibilitar aos estudantes a oportunidade de conhecer culturas diversas e validar a própria cultura dos educandos por meio da criação, apresentamos uma discussão crítico-reflexiva sobre a construção de uma ponte entre literatura e algoritmos ou, em um recorte mais detalhado, uma conexão entre literatura nacional e ensino de algoritmos. Em uma escola de ensino técnico, em um curso de nível médio integrado ao ensino técnico em Informática, propusemos aos alunos do segundo ano um projeto interdisciplinar para a unidade curricular de Algoritmos II, em conjunto com a unidade de Língua Portuguesa.

\section{FundamentaçÃo TEÓRICA}

Segundo Xavier e Silva (2015), com o surgimento de tecnologias como a fotografia, o cinema, a televisão e com a criação de outras, como as mídias digitais, as formas de expressão e comunicação se transformaram. Os meios de leitura e produção textual também passaram por remodelagens, percorrendo um caminho desde a Antiguidade Clássica até a Contemporaneidade. Ainda, de acordo com as autoras, a arte literária, que era cantada e entoada em rituais e jogos no século VIII a.C., passa a se mostrar presente em outros meios e suportes, deixando de ser somente ouvida e cantada, e passando a ser lida em dimensões que abordam a reunião de múltiplas linguagens, como a linguagem verbal, a linguagem visual e a sonoridade, sejam elas separadas ou mescladas, constituindo aparatos intersemióticos.

A relação entre a educação e as novas ferramentas tecnológicas tem alimentado investigações acadêmicas acerca dos benefícios que podem ser alcançados, bem como sobre as dificuldades encontradas no ambiente escolar para garantir a efetiva integração das TICs no currículo, de modo a caracterizar as mudanças da modernidade.

Em Educação e mudança, Paulo Freire (2014) afirma que os atos de criação, recriação e decisão do homem dinamizam o mundo a partir das relações que ele estabelece com a realidade por estar com ela e por estar nela. Segundo Freire, o homem vai dominando a realidade, humanizando-a e acrescentando a esta algo da qual ele mesmo é o fazedor: a cultura.

O ensino de novas ferramentas tecnológicas não deve ter como objetivo somente o "aprender a usar", mas, sim, saber como dominar e criar artefatos significativos com elas. Obter fluência em novas tecnologias envolve não apenas saber usar ferramentas tecnológicas, mas também saber construir artefatos significativos a partir dessas ferramentas (PAPERT, 1993). A adoção de uma metodologia na qual os discentes criam e compartilham seus próprios artefatos neste caso, os jogos - é apoiada por alguns pesquisadores por engajar e motivar estudantes no processo de aprendizagem, além de incentivar a construção do conhecimento por meio de atividades práticas (PAPERT; HAREL, 1991; KAFAI, 2006). A construção de jogos em sala de aula pelos alunos é uma metodologia rara e pouco empregada, embora haja registros de que essa ideia vem sendo utilizada por quase três décadas (KAFAI; BURKE, 2015). 
A ideia de Papert (1993) de que devemos produzir artefatos significativos com as ferramentas digitais é reafirmada por Pellim (2019). Em sua obra, Pellim (2019, p. 57) declara que a evolução das tecnologias de informação e comunicação revela transformações nos modos pelos quais produzimos sentidos e, com isso, os usuários deixam de ser triviais consumidores para se tornarem, também, de certa forma, produtores de conteúdos significativos que são compartilhados em uma abrangência global.

Diante do contexto de que os meios de leitura e produção textual passaram por remodelagens, e de que um aprendizado significativo oportuniza a criação (pelos estudantes) de artefatos significativos (para os estudantes), vimo-nos diante da oportunidade de realizar um projeto interdisciplinar que contemple a releitura de textos literários na criação de jogos digitais, os quais podem ser chamados de adaptação transmídia (CARDOZO; MATTAR, 2017).

A adaptação transmídia de seriados de televisão (ou desenhos animados) para jogos é comum, e a década de 1990 presenciou muitos desenhos animados baseados em jogos digitais. Entretanto, nos últimos anos, parece estar diminuindo a quantidade de produções com adaptações desta natureza (DEVIDES, 2018; CARDOZO; MATTAR, 2017).

Em relação às obras literárias, as adaptações envolvendo histórias em quadrinhos e jogos digitais são comuns nas duas direções. Enquanto isso, os livros baseados em jogos digitais são cada vez mais populares; porém, quando observamos a direção oposta, a adaptação de um livro para um jogo digital não é tão frequente (DE-AZEVEDO, 2018; MASTROBERTI, 2016).

$\mathrm{Na}$ abordagem didática proposta, foi sugerido aos discentes que desenvolvessem jogos digitais baseados em obras literárias previamente recomendadas, e que os jogos desenvolvidos tivessem regras livres desde que apresentassem uma narrativa com os personagens. Desse modo, poderiam ser adaptadas na implementação computacional, facilitando, assim, a adaptação transmídia dos livros para os jogos.

Segundo Papert e Harel (1991), o conceito do construcionismo pondera o aprendizado como um processo no qual os aprendizes constroem seus conhecimentos por meio da interação com o objeto de estudo. A visão construcionista coloca a produção de jogos nas mãos dos alunos para estimular a busca de conhecimento, recorrendo ao desenvolvimento de seus próprios jogos. Nessa perspectiva, o intuito da atividade de construção de jogos é apoiar tal metodologia, proporcionando um cenário de aprendizagem apropriado. Sendo assim, os educadores construcionistas se empenham em proporcionar aos discentes mais oportunidades para desenvolver seus jogos e, paralelamente, construir novas relações com o conhecimento durante o processo, em vez de simplesmente incorporar lições diretamente dentro dos jogos (KAFAI, 2006).

Quando voltamos o olhar para os cursos de Tecnologia da Informação (TI), muitos educadores identificam e aproveitam os interesses e a familiaridade da geração mais jovem por jogos digitais, e demais conteúdos relacionados, em suas disciplinas iniciais de programação (BATISTA, 2017). Os jogos são utilizados em unidades curriculares de programação de diversas maneiras, que vão desde jogar até analisar e desenvolver jogos. Kafai e Burke (2015) declaram que poucos educadores optam por trilhar um caminho diferente quando o assunto é o uso de jogos na educação. Este caminho, o de criar jogos em vez de jogá-los para 
aprender, pode parecer mais dificil de trilhar quando o docente não tem familiaridade com jogos e suas particularidades.

Alguns autores de trabalhos encontrados na literatura também propõem a construção de jogos como ferramenta auxiliar no processo de ensino e aprendizagem, seja na sua forma original, seja adaptando os jogos para alcançar seus objetivos de aprendizagem específicos. Gomes et al. (2019) apresentam uma proposta de elaboração do conhecimento educacional por meio da inserção de jogos no processo de ensino e aprendizagem na educação de alunos do ensino fundamental, tendo como foco a criação de jogos lúdicos matemáticos para consolidar a relevância da temática.

Rafaela Chaves, Josefa Lira-da-Silva e Rejâne Lira-da-Silva (2017) relatam a experiência da criação de jogos sobre Paleontologia por estudantes do ensino fundamental que produziram três jogos com considerável potencial didático. Podemos destacar neste trabalho a importância do papel do professor/orientador no processo de mediação do conhecimento paleontológico e desenvolvimento dos jogos. Segundo as autoras, os estudantes participaram de todo o processo de ensino e aprendizagem, dominando os conteúdos, elaborando os roteiros, produzindo os jogos e apresentando-os ao público-alvo.

Sobreira, Viveiro e d'Abreu (2018) descrevem uma experiência de criação de jogos digitais por estudantes do ensino fundamental na qual o professor teve um importante papel de designer da atividade, oportunizando a concepção de um ambiente construcionista em um projeto que abrangeu a aprendizagem criativa na construção de jogos digitais. Nessa experiência, Sobreira, Viveiro e d'Abreu (2018) relatam a utilização do conteúdo de Energia e o uso da ferramenta Scratch ${ }^{1}$ para programação dos jogos digitais. De acordo com as análises dos autores, a proposta favoreceu a aprendizagem dos conteúdos de Ciências, bem como suas interações com as tecnologias digitais utilizadas. Nesse tipo de abordagem, os estudantes têm a oportunidade de se envolver em ações que favorecem tanto o letramento científico quanto o digital, reconhecendo-se como produtores de artefatos significativos (nesse caso, jogos digitais), enriquecidos em contexto e atrativos em propostas relevantes.

Andrade et al. (2016) descrevem uma abordagem para estimular o estudo de programação no ensino médio por meio do desenvolvimento de jogos, utilizando a ferramenta Scratch, dando suporte à multidisciplinaridade intrínseca ao processo. De acordo com os autores, o processo de desenvolvimento de um jogo trabalha habilidades multidisciplinares, como: programação, trabalho em equipe, criticidade e criatividade. Nesta obra, Andrade et al. (2016) informam que os resultados obtidos em suas análises apontam que os alunos desenvolveram habilidades cognitivas relacionadas à programação e empregaram heurísticas de jogabilidade nos jogos produzidos.

Como observamos, a construção de jogos auxilia o desenvolvimento de outras metodologias facilitadoras do processo de ensino e aprendizagem para educadores e educandos de diferentes áreas do conhecimento, como Matemática (GOMES et al., 2019), Ciências/Paleontologia (CHAVES; LIRA-DA-SILVA; LIRA-DA-SILVA, 2017), Ciências /Energia (SOBREIRA; VIVEIRO, D'ABREU, 2018) e nos conteúdos abordados no ensino médio (sem especificar a unidade curricular trabalhada) (ANDRADE et al., 2016).

1 Disponível em: <https://scratch.mit.edu/>. 
Para a execução dessa abordagem interdisciplinar, que se trata de uma adaptação transmídia de livros para jogos digitais, foram selecionadas algumas obras de autores nacionais para servirem como inspiração no desenvolvimento dos jogos. As obras selecionadas estão detalhadas na próxima seção.

\section{Percurso metodológico}

\section{Caracterização do ambiente de aplicação do projeto}

Este projeto interdisciplinar foi realizado em um Instituto Federal de Educação, Ciência e Tecnologia, em um curso de Informática de nivel técnico, ofertado na modalidade integrada ao ensino médio. Esse curso tem duração de três anos, em período integral, e recebe alunos concluintes do ensino fundamental. As duas unidades curriculares que participaram desse projeto foram Língua Portuguesa e Algoritmos II, ambas pertencentes ao segundo ano desse curso. A turma de alunos participantes era formada por 23 estudantes com faixa etária entre 14 e 15 anos, sendo estes considerados "nativos digitais", conforme divisão de grupos proposta por Prensky (2012).

\section{Componente curricular: Língua Portuguesa}

Na unidade curricular de Língua Portuguesa, como lingua materna, na forma integrada ao ensino médio, desenvolve-se um programa que permite ao estudante compreender o mundo em que vive, tendo a construção do conhecimento a partir de seu conhecimento de mundo, do conhecimento sistêmico e do conhecimento sobre textos, guiando-se por temas, como compreensão escrita, produção escrita e conhecimento léxico-semântico em língua portuguesa.

Um dos meios didático-pedagógicos utilizados para aprimoramento da compreensão escrita é a leitura e interpretação de textos e obras literárias. Como forma de oportunizar o contato dos discentes com obras escritas por autores nacionais, são sugeridas, regularmente, obras literárias de autores contemporâneos, bem como obras de autores do século XX. Para este projeto interdisciplinar foram sugeridas as seguintes obras e seus respectivos autores:

- Dom Casmurro, Machado de Assis

- Macunaíma, Mário de Andrade

- O Alquimista, Paulo Coelho

- Capitães da Areia, Jorge Amado

- Memórias póstumas de Brás Cubas, Machado de Assis

- A hora da estrela, Clarice Lispector

- Grande Sertão: Veredas, Guimarães Rosa

- Pauliceia Desvairada, Mário de Andrade

- As três Marias, Rachel de Queiroz

Como forma de avaliação de aprendizagem, os alunos deveriam expor seus jogos no formato de apresentação oral, além de realizar um fichamento literário simples. Nessa apresentação oral, seriam observados os seguintes aspectos: clareza, postura, recursos gráficos utilizados na apresentação, tempo de apresen- 
tação e divisão do trabalho entre a dupla (ou trio). No fichamento literário simples seriam observados os aspectos: dados sobre o autor, qualidade da escrita, qualidade do conteúdo e atenção às informações da obra.

\section{Componente curricular: Algoritmos II}

Na unidade curricular de Algoritmos II, os alunos têm acesso à aplicação de conceitos de programação de computadores, utilizando uma linguagem de programação específica para o desenvolvimento de softwares. Os tópicos abordados nessa unidade podem variar em cada instituição de ensino, porém os objetivos de aprendizagem são comuns entre elas (BATISTA, 2017, p. 50). Entre os objetivos de aprendizagem, podemos destacar conceitos como entrada e saída de dados, utilização de variáveis, estruturas condicionais, estruturas de repetição e manipulação de arquivos.

Para a realização desse projeto interdisciplinar, além dos conceitos previstos na ementa da unidade curricular de Algoritmos II, foram ministrados conceitos básicos sobre desenvolvimento de jogos digitais. Esses tópicos sobre produção de jogos não fazem parte da ementa da unidade curricular, mas foram essenciais para que os alunos pudessem produzir os seus artefatos digitais. São tópicos específicos da área de desenvolvimento de jogos digitais, mas que estão plenamente relacionados aos conceitos de programação vistos anteriormente. Sendo assim, podemos dizer que esses conceitos de desenvolvimento de jogos são considerados aplicações práticas dos tópicos essenciais de programação de computadores.

Foram ministrados aos alunos alguns tópicos essenciais sobre desenvolvimento de jogos, tais como: receber informações/ações do usuário/jogador, manipulação de imagens e áudios, construção de um laço de repetição principal, ação e reação (comportamento do jogo de acordo com ações do usuário/jogador), conforme categorização de Sicart (2008). O Quadro 1 mostra a relação entre os conceitos de desenvolvimento de jogos digitais e os conceitos de programação de computadores.

Quadro 1 - Relação entre tópicos de programação e criação de jogos

\begin{tabular}{|c|c|}
\hline $\begin{array}{c}\text { Conceitos de desenvolvimento } \\
\text { de jogos digitais (SICART, 2008) }\end{array}$ & $\begin{array}{c}\text { Conceitos de programação de } \\
\text { computadores (BATISTA, 2017) }\end{array}$ \\
\hline Receber informações/ações do usuário/jogador & Entrada e saída de dados; variáveis \\
\hline Manipulação de imagens e áudios & Manipulação de arquivos; variáveis \\
\hline Laço principal do jogo & Estruturas de repetição; variáveis \\
\hline Ação e reação & Estruturas condicionais; variáveis \\
\hline
\end{tabular}

Fonte: Elaborado pelos autores.

\section{Proposta de ATIVIdAde INTERdisciplinaR: CRIAÇÃo DE UM JOGO DIGITAL}

Os jogos digitais fazem parte da vida dos jovens neste mundo novo e conectado. São artefatos lúdicos digitais com os quais os nossos alunos já estão familiarizados. Nesse contexto, foi proposto aos discentes, como parte do projeto interdisciplinar, o desenvolvimento de um artefato digital (jogo digital), porém com a temática baseada em uma das obras recomendadas descritas anteriormente. 
Como elemento da proposta, foi solicitada aos alunos uma releitura do texto literário como forma de jogo digital, ou seja, não havia a necessidade de uma reprodução completamente fiel à obra original. Ajustes e adaptações foram permitidos; por exemplo, caso não houvesse personagens suficientes na obra original para compor o quadro de personagens do jogo digital, novos personagens poderiam ser criados pelos alunos. Assim, também foram permitidos adaptações e ajustes relacionados a cenários e enredo.

\section{Avaliação de APRENDizagem}

Concernente ao componente curricular Algoritmos II, a avaliação de aprendizagem foi realizada pelo docente responsável, verificando junto aos artefatos produzidos se estes atendiam ou não aos requisitos solicitados na proposta de atividade. Os requisitos analisados foram:

- aplicação de recursos gráficos (quantidade e qualidade das imagens utilizadas);

- uso de recursos de áudio (quantidade e qualidade dos efeitos sonoros, músicas de fundo utilizadas no jogo);

- utilização de laço principal (se o jogo oferecia a opção de "jogar novamente" ao término de uma partida);

- presença de aleatoriedade no jogo (a cada partida, o comportamento diferenciado do jogo em relação às ações do usuário, de modo que o jogo não se tornasse repetitivo e entediante);

- jogabilidade (se o jogo estava jogável, ou seja, sem erros de programação, sem bugs).

Na unidade curricular de Língua Portuguesa, a avaliação de aprendizagem foi realizada pela docente responsável, verificando junto aos artefatos produzidos se estes atendiam ou não aos requisitos solicitados na proposta da atividade. Os requisitos analisados foram:

- grafia correta dos termos em português;

- enredo narrativo adaptado corretamente;

- preservação do enredo da obra recomendada (houve fuga do tema?).

Além desses requisitos observados, ainda na unidade curricular de Lingua Portuguesa, os alunos fizeram exposição de seus jogos no formato apresentação oral. Nessa apresentação oral, foram observados os aspectos de clareza, postura, recursos gráficos utilizados na apresentação, tempo de apresentação, divisão do trabalho entre a dupla (ou trio).

\section{AnÁlises e discussões}

Neste artigo, apresentamos o ponto de vista do educador, em face da proposta do projeto interdisciplinar. Em trabalhos futuros, apresentaremos a perspec- 
tiva do educando desse mesmo projeto. Do ponto de vista docente, o que se notou foi um engajamento por parte dos discentes envolvidos na proposta, tanto na leitura da obra recomendada quanto no desenvolvimento do jogo digital.

Todas as duplas e trios apresentaram o jogo pronto com todos os elementos que foram solicitados na proposta de atividade. A Figura 1 demonstra algumas imagens (screenshots) das telas iniciais dos jogos produzidos pelos alunos.

Figura 1 - Imagens da tela inicial de alguns jogos produzidos
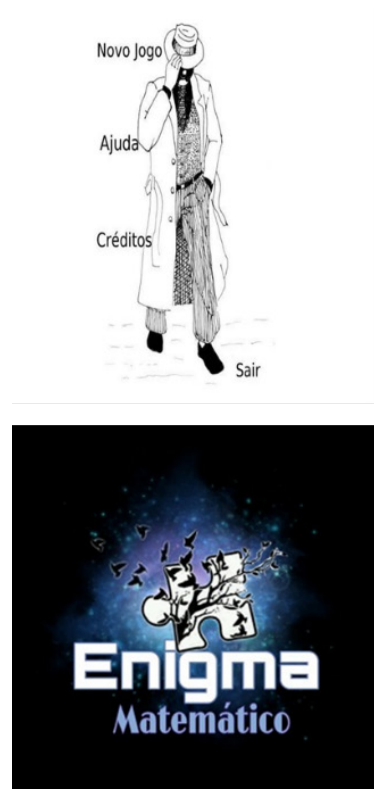
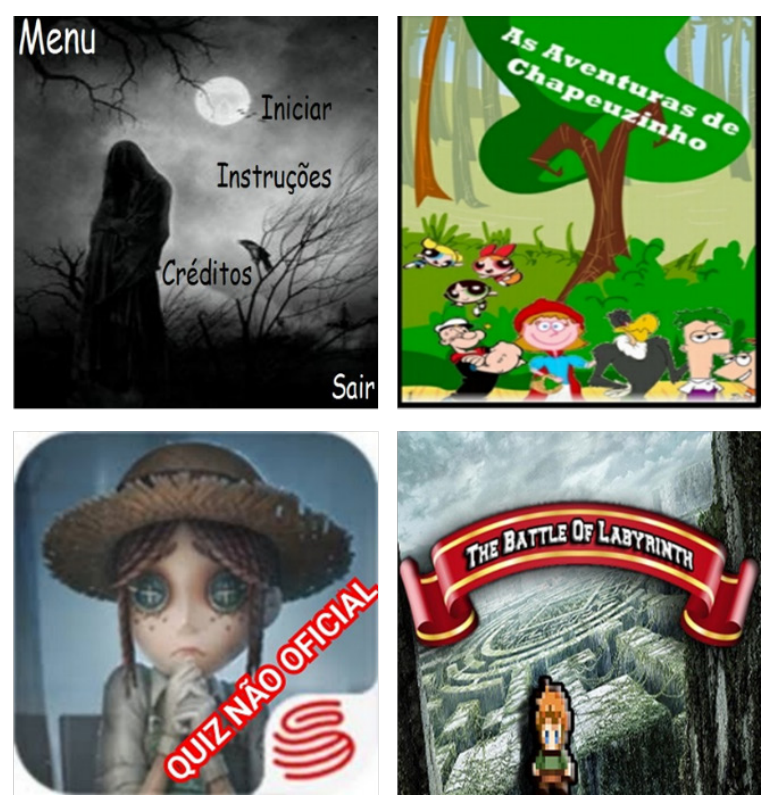

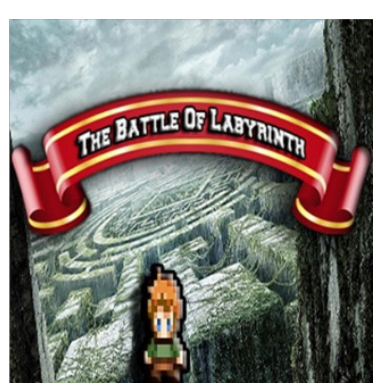

Com relação ao componente curricular Lingua Portuguesa, em atividades tradicionais anteriores, verificou-se que nem todos os alunos procediam com a leitura completa das obras propostas. Entenda-se por atividades tradicionais as tarefas de leitura de obras e, posteriormente, a confecção de um fichamento do livro, ou até mesmo de uma prova escrita ou arguição oral. Entretanto, na atividade interdisciplinar, podemos apurar que o engajamento na leitura completa das obras foi integral. Podemos inferir que, para a produção de outro meio midiático, como um jogo digital, por exemplo, o desenvolvedor (nesse caso, o aluno) realmente se empenhou em conhecer a obra tema da sua produção, em todos os seus detalhes, tais como enredo, cenários e personagens.

Quanto ao componente curricular Algoritmos, o que se percebeu foi o aumento do entusiasmo em produzir uma aplicação prática. Em projetos tradicionais anteriores eram notáveis a falta de interesse e a falta de entusiasmo diante das aplicações propostas. Por atividades tradicionais de Algoritmos, entenda-se a produção de pequenas aplicações digitais, como uma calculadora aritmética simples, um aplicativo para cálculo de índice de massa corpórea (IMC), um aplicativo que converte números em base decimal para base binária, entre outros. No entanto, ao propor aos alunos a produção de um jogo digital, percebemos que o interesse na tarefa proposta foi maior do que nas atividades tradicionais. 
Os jogos digitais são artefatos que atraem o interesse dos alunos nessa faixa etária (PRENSKY, 2012). Estudos mostram que o uso de jogos no processo de ensino e aprendizagem tem se mostrado muito efetivo (BATISTA; CONNOLLY; ANGOTTI, 2016; SENA et al., 2016; CHAUDY; CONNOLLY, 2019).

Sobre a diferença de interesse dos alunos em relação às atividades tradicionais e à produção de jogos, pudemos perceber que durante o desenvolvimento de aplicações clássicas, a procura por atendimento extraclasse era muito baixa cerca de um aluno por semana (em uma turma de 23 alunos). Entretanto, durante o período de desenvolvimento dos jogos digitais temáticos, a procura por atendimento extraclasse foi muito alta: aproximadamente 15 alunos por semana procuraram o monitor da unidade curricular de Algoritmos.

Quando tratamos de desenvolvimento de jogos digitais, todos os conceitos de programação de computadores (entrada e saída, variáveis, estruturas condicionais, estruturas de repetição, manipulação de arquivos) são aplicados na criação desses artefatos. Essa aplicação prática aborda todos os conceitos ministrados em sala de aula, de modo que os alunos têm a oportunidade de colocar em prática os conteúdos e, assim, alcançar os objetivos de aprendizagem propostos.

Depois do encerramento da atividade, notou-se nos discentes um aumento no interesse e na procura por materiais e atividades relacionados à produção de jogos. Alguns alunos - que continuaram a se interessar por criação de jogos - posteriormente apresentaram seus trabalhos (outros jogos digitais) em eventos e congressos acadêmicos (BATISTA; ALMEIDA; SILVA, 2019; PIMENTEL et al., 2019; BATISTA et al., 2019; BATISTA; MARTINS; LELLIS, 2019).

\section{Conclusões}

Neste artigo, apresentamos uma conexão em literatura nacional e algoritmos aplicados no desenvolvimento de jogos digitais. Em um projeto interdisciplinar entre as unidades curriculares de Lingua Portuguesa e Algoritmos, foi proposto aos alunos o desenvolvimento de um jogo digital com a temática baseada em uma obra de autoria nacional. Durante o desenvolvimento do projeto interdisciplinar, verificamos, do ponto de vista docente, o aumento no comprometimento dos alunos com as atividades propostas, em ambas as unidades curriculares. Verificamos também o aumento no interesse em procurar atendimento extraclasse (monitorias) para aprimoramento de conhecimentos ministrados em sala de aula. Os jogos produzidos foram apresentados em um evento interno da instituição e compartilhados com outros alunos da instituição, seguindo as ideias construcionistas de Seymour Papert.

É relevante ressaltar a importância desse tipo de ação no contexto educacional, uma vez que esse modelo de atividade pode conquistar a atenção e a dedicação dos alunos, tornando o processo educativo ainda mais prazeroso e eficiente. Quando o processo educativo se torna eficiente, um dos frutos colhidos é o aprofundamento da relação da escola com os alunos e vice-versa.

Neste artigo, descrevemos o ponto de vista docente desse projeto interdisciplinar. Para os trabalhos futuros, pretendemos apresentar o ponto de vista discente, com relatos colhidos por meio de questionários, que poderão retratar o 
grau de engajamento pessoal de cada estudante em relação a ambas as unidades curriculares perante o projeto proposto. Outros trabalhos vertentes, frutos desse projeto, podem abordar a construção de conexões entre algoritmos e literatura estrangeira (inglesa ou espanhola), com a produção de jogos com temáticas fundamentadas em obras de autores internacionais.

\section{(RE)READINGS OF BRAZILIAN NOVEL BOOKS IN THE DEVELOPMENT OF DigitAL GAMES}

Abstract: In this paper, we describe the possibility of establishing a solid connection between literature and algorithms. We report here an interdisciplinary academic experience involving students from the Computer Science course, in which they performed the transmedia adaptation of literary works by national authors to digital games produced by students themselves. The analyzes show that this didactic-pedagogical action improved student engagement concerning the content of the curricular units, and establishes an effective connection between literature and algorithms.

Keywords: Brazilian literature. Algorithms. Digital games. Pedagogical practices. Interdisciplinarity.

\section{REFERÊNCIAS}

ANDRADE, R. et al. Uma proposta de oficina de desenvolvimento de jogos digitais para ensino de programação. In: CONGRESSO BRASILEIRO DE INFORMÁTICA NA EDUCAÇÃO (CBIE 2016), 5., 2016, Uberlândia. Anais [...]. Porto Alegre: Sociedade Brasileira de Computação, 2016.

BATISTA, A. L. F. Guia para ensino de programação baseado em construção de jogos. 2017. 138 f. Tese (Doutorado em Educação Científica e Tecnológica) Universidade Federal de Santa Catarina, Florianópolis, 2017. Disponivel em: https://repositorio.ufsc.br/handle/123456789/187055. Acesso em: 25 mar. 2020.

BATISTA, A. L. F.; ALMEIDA, E. S.; SILVA, M. M. Jogo para ensino de metodologia científica: proposta de game design. In: SIMPÓSIO BRASILEIRO DE JOGOS E ENTRETENIMENTO DIGITAL (SBGAMES), 2019, Rio de Janeiro. Anais [...]. Rio de Janeiro: Sociedade Brasileira de Computação, 2019. v. 1, p. 1176-1179.

BATISTA, A. L. F.; BAZZO, W. A. Questões contemporâneas e desenvolvimento de aplicativos móveis: onde está a conexão? Revista Brasileira de Ensino de Ciência e Tecnologia, v. 8, n. 4, 2015.

BATISTA, A. L. F.; CONNOLly, T.; ANGOTTI, J. A. P. A framework for games-based construction learning: a text-based programming languages approach. In: EUROPEAN CONFERENCE ON GAMES BASED LEARNING, 10., 2016, Paisley. Proceedings [...]. Paisley, 2016. p. 815-823.

BATISTA, A. L. F.; MARTINS, R. G.; FILHO, A. P. N. SQL Planet: a game proposal to teach SQL language. In: ANNUAL INTERNATIONAL CONFERENCE OF EDUCATION, RESEARCH AND INNOVATION, 12., 2019, Seville. Proceedings [...]. Seville, 2019. v. 1, p. 4372-4377. 
BATISTA, A. L. F.; MARTINS, R. G.; LELLIS, J. J. V. Game-based construction learning: creating digital games for chemistry education. In: ANNUAL INTERNATIONAL CONFERENCE OF EDUCATION, RESEARCH AND INNOVATION, 12. 2019, Seville. Proceedings [...]. Seville, 2019. v. 1, p. 4378-4383.

BATISTA, A. L. F.; NEHME FILHO, A. P.; PIMENTEL, D. R.; MARTINS, R. G. SQL Planet: jogo online para ensino de linguagem SQL. In: SIMPÓSIO BRASILEIRO DE JOGOS E ENTRETENIMENTO DIGITAL (SBGAMES), 2019, Rio de Janeiro. Anais [...]. Rio de Janeiro: Sociedade Brasileira de Computação, 2019. v. 1, p. $1220-1223$.

CARDOZO, M.; MATTAR, J. Adaptação transmídia de/para games: revisão de literatura. In: SIMPÓSIO BRASILEIRO DE JOGOS E ENTRETENIMENTO DIGITAL (SBGAMES), 16., 2017, Curitiba. Anais [...]. Curitiba: Pontificia Universidade Católica do Paraná, 2017.

CASTELLS, M. A sociedade em rede - a era da informação: economia, sociedade e cultura. São Paulo: Paz e Terra, 2010.

CHAUDY, Y.; CONNOLLY, T. M. Specification and evaluation of an assessment engine for educational games: Integrating learning analytics and providing an assessment authoring tool. Entertainment Computing, v. 30, n. 100294, 2019.

CHAVES, R. S.; LIRA-DA-SILVA, J. R.; LIRA-DA-SILVA, R. M. A produção de Jogos Paleontológicos por bolsistas de iniciação científica júnior para o Ensino de Ciências. Enseñanza de las ciencias: revista de investigación y experiencias didácticas, n. extra, p. 1077-1082, 2017.

CORMEN, T. H. et al. Algoritmos: teoria e prática. Rio de Janeiro: Campus Elsevier, 2002.

DE-AZEVEDO, J. Adaptación literaria Transmedia en juego: fundamentos teóricos para un itinerario experimental para juego digital de Macunaíma, de Mário de Andrade. Razón y palabra, v. 22, n. 2, p. 104-143, 2018.

DEVIDES, D. C. Lendo jogos: adaptação literária para jogos digitais. RETEC Revista de Tecnologias, v. 11, n. 2, p. 54-58, 2018.

DOS SANTOS, F. M. A. A produção de textos em ambientes digitais: possíveis caminhos para o ensino da escrita. Todas as Letras - Revista de Língua e Literatura, São Paulo, v. 20, n. 3, p. 196-211, set./dez. 2018.

FREIRE, P. Educação e mudança. 12. ed. São Paulo: Paz e Terra, 2014.

GOMES, A. L. P. et al. Construção e aplicação de jogos para o ensino e aprendizagem dos conceitos matemáticos. Fórum de Integração Ensino, Pesquisa, Extensão e Inovação Tecnológica do IFRR, v. 6, n. 1, 2019.

KAFAI, Y. B. Playing and making games for learning instructionist and constructionist perspectives for game studies. Games and Culture, v. 1, n. 1, p. 36-40, 2006.

KAFAI, Y. B.; BURKE, Q. Constructionist gaming: Understanding the benefits of making games for learning. Educational Psychologist, v. 50, n. 4, p. 313-334, 2015. LÉVY, P. Cibercultura. São Paulo: Editora 34, 2005.

MARTINS, V. B. Releituras digitais nas aulas de Língua Portuguesa do curso de Letras. Todas as Letras - Revista de Lingua e Literatura, São Paulo, v. 17, n. 1, 2015. 
MASTROBERTI, P. Adaptação, versão ou recriação? Mediações da leitura literária para jovens e crianças. Semioses, v. 5, n. 2, p. 104-122, 2016.

PAPERT, S. The Children's machine: rethinking school in the age of the computer. New York: Basic Books, 1993.

PAPERT, S; HAREL, I. Situating constructionism. Constructionism. Norwood: Ablex Publishing Corporation, 1991.

PELLIM, T. (Multi) letramentos digitais no ensino de lingua inglesa no ensino médio técnico. Todas as Letras - Revista de Lingua e Literatura, v. 21, n. 2, 2019.

PIMENTEL, D. R. et al. RPG colaborativo para experimentação de vida acadêmica. In: SIMPÓSIO BRASILEIRO DE JOGOS E ENTRETENIMENTO (SBGAMES), 2019, Rio de Janeiro. Anais [...]. Rio de Janeiro: Sociedade Brasileira de Computação, 2019. v. 1, p. 1216-1219.

PRENSKY, M. From digital natives to digital wisdom: hopeful essays for $21 \mathrm{st}$ century learning. Thousand Oaks: Corwin Press, 2012.

SENA, S. et al. Aprendizagem baseada em jogos digitais: a contribuição dos jogos epistêmicos na geração de novos conhecimentos. RENOTE - Revista Novas Tecnologias na Educação, v. 14, n. 1, p. 1-11, 2016.

SERRA, L. G.; SANTARÉM, J. E. Modelos de negócios, bibliotecas e livros digitais. Informação \& Sociedade, v. 27, n. 3, 2017.

SICART, M. Defining game mechanics. Game Studies, v. 8, n. 2, p. 1-14, 2008. SOBREIRA, E. S. R.; VIVEIRO, A. A.; D’ABREU, J. V. V. Aprendizagem criativa na construção de jogos digitais: uma proposta educativa no ensino de ciências para crianças. Tecné Episteme y Didaxis: TED, n. 44, p. 71-88, 2018.

SOUZA, M. J. M. de. Literatura jovem adulto, projeto de extensão e a democratização do conhecimento: a leitura como um direito cidadão. Pensares em Revista, São Gonçalo, n. 17, 2020.

XAVIER, N. R. G. D.; SILVA, D. C. S. Diálogos intersemióticos: criação e fruição de poesia em meio digital. In: EDUCERE - CONGRESSO NACIONAL DE EDUCAÇÃO, 12., 2015, Curitiba. Anais [...]. Curitiba: Pontificia Universidade Católica do Paraná, 2015. 